\title{
O SEMINÁRIO DE HABITAÇÃO E REFORMA URBANA: ANTECEDENTES DE UMA POLÍTICA PARA HABITAÇÃO POPULAR
}

\section{The Urban Reform And Housing Seminar: The Background For Low Income Housing Policy In Brazil}

\author{
Marlice Nazareth Soares de Azevedo \\ Universidade Federal Fluminense \\ marliceazevedo@globo.com
}

José Francisco Bernardino Freitas

Universidade Federal Fluminense

jfbfreitas@gmail.com

\section{Resumo}

Esse estudo apresenta o contexto por que passava o País e, aquele porque experimentavam as cidades brasileiras na oportunidade de realização, em 1963, do Seminário de Habitação e Reforma Urbana (s.HRu). Examina suas proposições, em particular as associadas às questões habitacionais. Avalia os resultados do evento e suas incorporações na Lei Federal, já do período de ditadura militar, que institui o Banco Nacional de Habitação em 1964. Por fim, esboça um panorama comemorativo do jubileu do evento, o $Q+50$,também promovido pelo IAB, em diversas regiões do País em 2013, e constata a diluição do tema habitação, mesmo que não satisfatoriamente solucionado, diante do ampliado espectro de problemas e dificuldades por que passam as cidades brasileiras da atualidade.

\section{Palavras-chave}

Política habitacional, Seminário de habitação, Reforma urbana, História da cidade, Jubileu do s.HRu.

\begin{abstract}
This study presents the context in which Brazilian cities and society were going through at the time of the realization of the Urban Reform and Housing Seminar (s.HRu) in 1963. It aims at evaluating its propositions, in special those associated to housing, assessing its results towards the issue of the Federal Law that creates the National Housing Bank in 1964 during the military dictatorship. Finally it gives a broad view of the event that celebrated the jubilee of the s.HRu,also promoted by the Brazilian Architects Institute (IAB), around various regions of the country in 2013. The $Q+50$ confirms the weakening of the housing theme, although not fully contemplated
\end{abstract}


by government policies, in the face of the widened spectrum of problems and difficulties that Brazilian cities experience.

\section{Keywords}

Housing policy, Housing seminar, Urban reform, History of the city, Jubilee of the s.HRu.

\section{INTRODUÇÃO}

O denominado período "desenvolvimentista" que se iniciou no Brasil após a Segunda Guerra Mundial foi marcado por importantes reformas sociais introduzidas nos primeiros anos do Governo de Getúlio Dornelles Vargas. Característica relevante desse período foi a movimentação das atividades econômicas do meio rural para o urbano. Nesses anos as cidades desempenham papel fundamental nas políticas de desenvolvimento econômico e social. Essas cidades, e com elas as políticas urbanas, passam a dominar e determinar os debates e a agenda das administrações públicas. Assim, o foco das reformas urbanísticas orientadas à otimização do complexo agroexportador predominante desde o fim do século XIX, se conduz, nessa segunda metade do século $X X$, no sentido de incorporar preocupações sociais de reprodução como habitação, transporte e infraestruturas urbanas.

A legislação e os instrumentos urbanísticos existentes não davam conta das elevadas taxas de urbanização e a consequente expansão territorial a que estiveram submetidas às cidades do País. Instrumentos urbanísticos que fossem além dos tradicionais códigos de obras e leis de zoneamento começaram a ser pensados para fazer frente a necessidades que iam além do simples controle do solo urbano, para incluir uma perspectiva de regulação mais social. Esses instrumentos necessitavam incorporar a questão da habitação, em particular a de natureza social, orientada aos trabalhadores que se dirigiam as áreas urbanas, da mesma maneira que a provisão de infraestrutura necessária a suas expansões.

O quadro em que se encontrava o País desde a Revolução de 1930 até esse momento, segundo Benevides (1975, p. 22) era o que denomina "instabilidade crônica" caracterizada por um conjunto de episódios que culminam com o suicídio do presidente Vargas (1954) e dão origem ao "golpe preventivo" do General Lott (1955) e a subsequente renúncia do presidente em exercício (1961).

Esse mesmo autor aponta que o presidente Juscelino Kubitschek tem seu início e fim de mandato (1955-1960) marcado por profundas crises. O clima de intensa efervescência política desencadeada pelo suicídio de Vargas torna 
desfavorável a situação de Kubitschek durante sua campanha eleitoral, ameaçada de veto militar.

Kubitschek foi, no entanto, o único presidente civil nesse período que conseguiu manter-se do início ao fim de seu mandato por meios constitucionais. Benevides (1975, p. 24) argumenta que durante seu mandato, o país experimenta um período de estabilidade política e aponta como um dos fatores responsáveis o uso político de seu Plano de Metas que atendia tanto aos interesses das elites quanto das massas.Diversos autores (Lafer, (1970), Araújo (1970), Jaguaribe (1969), Bresser Pereira (1968) dentre outros), compartilham desse ponto de vista e indicam o "estilo conciliatório" de Kubitschek em torno de sua política econômica como preponderante. Essa estabilidade vai, no entanto, ser ameaçada pela crise econômica gerada pelo próprio sucesso de seu Plano de Metas (i.e. endividamento externo) e o esgotamento de modelo de substituição de importações (BENEVIDES, 1975).

Após o período de euforia do governo Kubitscheck é realizada nova eleição em 1960 cujas regras eleitorais estabeleciam chapas independentes para a candidatura de presidente e vice-presidente. A vitória coube a Jânio Quadros pela União Democrática Nacional (UDN)e João Goulart, também vice-presidente de Kubitscheck, foi reeleito pelo opositor Partido Trabalhista Brasileiro (PTB).

O então presidente eleito adota uma política econômica e uma política externa que desagrada aos políticos do partido que o apoiou além de setores das Forças Armadas e outros segmentos sociais. Seu período de mandato teve a duração de sete meses e culminou com sua renúncia.

A renúncia de Jânio Quadros desencadeou uma crise institucional porque a posse do vice-presidente não era aceita pelos ministros militares e parte das elites dominantes, sob a alegação de que ele faria parte do comunismo internacional. Esse contexto de incertezas traz para o debate a necessidade de mudanças nas arraigadas estruturasdo País. Goulart é empossado em regime parlamentarista com o compromisso de realização de um plebiscito, que em 1963, condena esse regime e resulta na manutenção de João Goulart em regime presidencialista.

Vale, novamente, lembrar que se tratava de um período de profundas transformações que não se restringiam ao Brasil, mas que se estendiam pelos demais países da América Latina. Neste sentido, constata-se a mudança do pensamento social latino-americano por influência de teorias que tratavam de um diversificado painel com conteúdos que transitavam entre o reformismo modernizante e a posições revolucionárias (GORELIK, 2005, p. 115). As questões eram comuns; o incremento populacional, a migração rural/urbana, a industrialização e a crise na estrutura 
agrária, são alguns exemplos. Verificavam-se iniciativas relacionadas ao planejamento econômico descoladas das questões urbanas que não eram tratadas por medidas governamentais que correspondessem a um planejamento físico territorial consequente.Todos esses fatos contribuíam para o agravamento da crise urbana e de oferta de moradias.

É nesse conturbado ambiente que a direção nacional do Instituto de Arquitetos do Brasil (IAB) por meio dos departamentos do Rio de Janeiro e São Paulo (IAB-GB e IAB-SP) em conjunto com o Instituto de Previdência e Assistência dos Servidores do Estado (IPASE) tomam a iniciativa de promover, em 1963, o Seminário de Habitação e Reforma Urbana (s.HRu). O Seminário foi realizado, em duas etapas, uma no Estado do Rio de Janeiro e outra no de São Paulo, e objetivava alterações nos instrumentos de regulação e de mediação dos conflitos sociais urbanos, ensejando a inclusão de mecanismos de controle do mercado imobiliário. As instituições promotoras ratificavam assim, o entendimento de que a questão habitacional não poderia mais ser tratada como uma política setorial e sim como parte significativa do meio urbano, entendido como o lugar da produção e reprodução social de seus habitantes (QUINTO JR., 2003).

No escopo das preocupações dessas instituições, no que se relaciona a habitação, encontrava-se o debate de que esse problema, de escala nacional, deveria deixar de ter conotação assistencial e quantitativa e se tornar uma atribuição do governo. A abordagem pretendida pelos arquitetos seria o entendimento de que a questão devia extrapolar a visão do estrito espaço da casa. Seria necessário dar conta da edificação em comum acordo com outras edificações e estas com os espaços das ruas, praças, parques escolas e outros da esfera pública. Também alvo dessa preocupação seria a população que faz todas "estas coisas terem sentido" (INSTITUTO DE ARQUITETOS DO BRASIL, 1964). Significa contemplar os homens, seu trabalho e suas relações com o espaço e habitantes da cidade, em última instância questões administrativas, econômicas, físico-territoriais e sociais.

O resultado desse evento inclui princípios da política habitacional e de reforma urbana reunidos em uma proposta de criação de um órgão central federal, que dentre outras proposições deveria elaborar um plano nacional territorial e um plano nacional de habitação como explicitado a seguir.

Esse documentose inicia apresentando a conjuntura a que estavam submetidas às cidades brasileiras e por que passava o país quando da realização, em 1963, do Seminário de Habitação e Reforma Urbana (s.HRu). Avalia suas proposições, em particular, àquelas associadas às questões habitacionais. Analisa os resultados do 
evento e as incorporações à Lei Federal, já do período de ditadura militar, que institui o Banco Nacional de Habitação em 1964. Por fim, esboça um panorama do evento comemorativo do jubileu do s.HRu, também promovido pelo IAB, em diversas regiões do País em 2013, e verifica o esvaziamento do tema habitação. Esse tema, ainda que não adequadamente solucionado por políticas de natureza financeira ou mesmo social, se apresenta nesse evento, enfraquecido e sombreado, diante do, talvez, ampliado espectro de problemas e dificuldades que experimentam as cidades brasileiras da atualidade.

\section{ANTECEDENTESDO SEMINÁRIO DE HABITAÇÃo E REFORMA URBANA (s.HRu)}

Na reunião de seu Conselho Superior, em maio de 1963, em Porto Alegre, o Instituto de Arquitetos do Brasil (IAB), manifestou sua preocupação sobre a crise que atingia a cidade e a moradia. Já estava em andamento no Departamento do Rio de Janeiro (na época Guanabara - IAB-GB) e no de São Paulo (IAB-SP), propostas no sentido de dar continuidade a reuniões de debates para criar uma política urbana e habitacional.

O IAB-GB contava com o apoio do presidente do IPASE, que já tinha a intenção de promover uma linha de financiamento habitacional de caráter mais social. Neste sentido o IPASE fez contato com IAB para organizar uma reunião de âmbito nacional com ampla participação de órgãos governamentais, representantes da previdência social, profissionais liberais e entidades ligadas à questão habitacional. Previa-se também a participação de organismos internacionais, como a Organização das Nações Unidas (ONU), a Organização dos Estados Americanos (OEA) e o seu Centro Interamericano de Vivienda y Planeamiento Urbano (CINVA) com sede na Colômbia, além de outros representantes de países estrangeiros (INSTITUTO DE ARQUITETOS DO BRASIL, 1963a).

O resultado dessa reunião do Conselho Superior do IAB foi a recomendação a seus departamentos de uma única reunião, unindo esforços para a realização de um seminário com o nome de "Seminário de Habitação e Reforma Urbana - O Homem, sua Casa sua Cidade".

Como resultado é concebido um Seminário para ser realizado em duas etapas, com um único tema, no Rio de Janeiro e em São Paulo, porém, com características diferentes. No Rio de Janeiro reunir-se-iam no máximo 40 pessoas, em tempo integral, e baseando-se nos debates e nos documentos existentes, um Grupo de Trabalho deveria responder alguns aspectos da questão, a saber: a situação 
habitacional no país - a habitação e o aglomerado humano - reforma urbana medidas para o estabelecimento de uma política de planejamento urbano e de habitação e por fim, a execução dos programas traçados por política de planejamento urbano e de habitação.Os resultados dessa etapa seriam levados à discussão em São Paulo por meio de participação ampliada, buscando alcançar um documento com propostas que abrangessem todas as camadas sociais(INSTITUTO DE ARQUITETOS DO BRASIL, 1963a).

O mesmo documento aponta algumas características a que estariam sujeitas essas reuniões: a constituição dos grupos, o local e o alcance dos documentos recolhidos, que compreendia os estudos já realizados como dissertações, teses e depoimentos de profissionais envolvidos com o tema. O local das reuniões no Rio foi na própria sede do IPASE e a coordenação coube ao arquiteto Maurício Nogueira Batista e em São Paulo na sede do IAB-SP sob a coordenação do arquiteto Jorge Wilheim.

Esses encontros se deram no final de julho de 1963, reunindo não só arquitetos, mas também sociólogos, de diferentes partes do país, com ampla cobertura da imprensa e mobilizando a população em geral, todos compartilhando o mesmo ponto de vista em torno do tema e sensibilizados com os problemas relacionados à habitação e ao aproveitamento do território nacional (INSTITUTO DE ARQUITETOS DO BRASIL, 1963c).

Esse mesmo documento assinala que os debates colocaram em evidência que, até então, o problema da moradia era tratado como questão de ordem assistencial e quantitativa, de responsabilidade do governo, não revelando a verdadeira problemática, criando certa parceria que foi considerada viciosa entre a classe dominante e o governo, que escondia aspetos negativos da própria estrutura nacional. No campo da habitação e do uso do território observaram-se distorções na oferta habitacional, que se refletiam na proliferação de agrupamentos subnormais na maioria das cidades brasileiras, carência da infraestrutura, incapacidade das cidades de absorver a mão de obra resultante da migração de grandes contingentes populacionais expulsos pela estrutura agrária arcaica.

Cabe observar nesse documento do IAB, um aspecto relevante - a oposição identificada pelo próprio empresariado da indústria da construção, que indiretamente, sempre se beneficiou do lucro advindo da própria especulação do mercado imobiliário tanto da terra como da construção.

Cumpre ainda observar que o Editorial da revista do IAB põe em evidência que os profissionais arquitetos criticavam as discussões formais da arquitetura de caráter 
meramente estético e as divagações sobre as teses de composição arquitetônica racionalista ou organicista para se engajar em questões sociais e econômicas da produção arquitetônica. Em assim sendo, convida o profissional arquiteto a participar e se aglutinar em torno dos problemas que afligem a sociedade brasileira considerando que a moradia não é um problema somente do arquiteto, mas o seu equacionamento impõe a participação de diferentes campos do conhecimento. 0 Editorial advoga que o papel do arquiteto não deveria ser apenas projetar e construir o edifício que especula, nem a residência "[...] de jardins babilônicos que ostenta, discrimina e oprime". Fundamentalmente, "[...] o arquiteto foi feito para atender as necessidades básicas do habitat do homem"(INSTITUTO DE ARQUITETOS DO BRASIL, 1963c, p. 2).Essa tomada de posição reflete o momento que o país atravessa resultando em dois fatos que pontuam a luta pelo equacionamento do problema habitacional: a mensagem Presidencial ao Congresso Nacional e o Seminário de Habitação e Reforma Urbana promovido pelo Instituto de Arquitetos do Brasil e o Instituto de Previdência e Assistência do Estado (IPASE).

\section{AS DISCUSSÕES do SEMINÁRIO de habitAÇÃo E POLÍtICA URBANA (s.HRu)}

O s.HRu reuniu cerca de 200 pessoas nas suas duas fases, incluindo profissionais de diferentes formações e representantes de órgãos estaduais de planejamento e empresas industriais de economia mista. A primeira fase no Rio de Janeiro instalou-se no auditório do MEC, no dia 23 de julho de 1963, transferindo-se para o Hotel Quitandinha, no município de Petrópolis no Estado do Rio de Janeiro, onde quatro grupos de estudo analisaram e debateram temas, com um moderador e um relator, cujos relatórios foram encaminhados para debates em sessão plenária. A composição desses grupos foi a seguinte:

O Grupo I -A situação habitacional do país teve como moderador o economista Vinícius da Fonseca e relator o engenheiro Álvaro Milanez; o Grupo II $-A$ habitação e o aglomerado urbano apresentou, a cargo da coordenação dos trabalhos como moderador o arquiteto Jayme Zettel e o relator a assistente social Maria Lúcia Carvalho; o Grupo III -Reforma Urbana: medidas para o estabelecimento de uma política de planejamento urbano e de habitação -, foi conduzido pelo moderador arquiteto Joaquim Guedes e o relator Arquiteto Antônio Pedro Alcântara; e, o Grupo IV - A execução dos programas de planejamento urbano e de habitação trouxe o 
advogado Clóvis Garcia como moderador e como relator o arquiteto Jorge Wilheim(INSTITUTO DE ARQUITETOS DO BRASIL, 1963d).

A Sessão Plenária teve lugar no Hotel Quitandinha, tendo como presidente Álvaro Milanez, o orientador dos debates Vinicius da Fonseca e,como secretário o arquiteto Edgard Bittencourt. Os documentos parciais foram debatidos, emendados, aprovados e encaminhados à Comissão Relatora para elaborar o Relatório Final desta etapa, sintetizando os documentos dos quatro grupos e as resoluções do plenário. Compunha essa Comissão o advogado Clóvis Garcia, o arquiteto Jorge Wilheim e o economista Vinícius Fonseca.

Este Relatório foi apresentado na segunda etapa do seminário, em São Paulo. Aprovado em sua essência depois de debatido, o documento teve a redação final elaborada por uma comissão composta pelos arquitetos Alberto Xavier (IAB-RS), Joaquim Guedes (IAB-SP), Mauricio Nogueira Batista (IAB-GB) e o economista Vinicius da Fonseca. A sessão de encerramento, realizada no auditório da Universidade Mackenzie, contou com a presença do representante do Ministro Amaury Silva - Leo Monari - delegado do trabalho em São Paulo - que fez a leitura de mensagem do ministro -, deputados federais Almino Afonso, Franco Montoro, Fernando Santana, Rubens Paiva e Arthur Lima Cavalcanti, o presidente do IPASE Clidenor Freitas, o presidente do IAB Nacional Ícaro de Castro Melo, o presidente do IAB-SP Oswaldo Correa Gonçalves e representante do Governador de Pernambuco Miguel Arraes, 0 arquiteto Gildo Guerra (INSTITUTO DE ARQUITETOS DO BRASIL, 1963d, p. 17).

Fazia parte do texto do ministro Amaury Silva o seguinte pronunciamento: "[...] Tenho a convicção de que a mesma imposição de consciência que nos leva a defender a reforma agrária deve levar-nos a defender a reforma urbana - não para um futuro longínquo e indefinido, mas para esta geração, para este período de renovação das estruturas da sociedade brasileira". Em outro ponto do discurso afirma "[...] O Ministro do Trabalho, o deputado Franco Motoro, levantou em números o problema da habitação no Brasil, revelando dados impressionantes e estarrecedores, como os de que um terço da população do Rio de Janeiro e dois terços da população do Recife moram em habitações inteiramente inadequadas, a começar por favelas e mocambos". O ministro continua a traçar o quadro do problema por adiantar: "[...] Estou convencido de que este Seminário, o primeiro conclave sob o patrocínio oficial sobre o tema, sem disfarces, da reforma idealizada e promovida sob a inspiração do Ministro Almino Afonso, é o começo desse trabalho e, em certo sentido, o começo da própria reforma"(INSTITUTO DE ARQUITETOS DO BRASIL, 1963d, p. 19). Essas 
palavras mostram o engajamento do próprio governo em enfrentar o desafio proposto pelas instituições promotoras do evento.

Os textos elaborados e que foram finalmente encaminhados demonstram o engajamento político do Seminário. Esses incluíram elementos precursores de caráter igualitário que podem ter tido um efeito perverso e insuflado as instituições, corporações e elites econômicas e governantes na promoção do golpe militar de 1964, até porque o presidente João Goulart se apropria de algumas ideias contidas no documento final do s.HRu, em sua Mensagem encaminhada ao Congresso Nacional em 1964 como indicado abaixo.

\section{O DOCUMENTO FINAL DO SEMINÁRIO}

A segunda etapa do Seminário, responsável pela elaboração do documento final, ocorreu em São Paulo. Assinaram a lista de participação cerca de 120 pessoas, sendo que dos participantes que estiveram presentes a grande maioria era constituída por arquitetos - mais de $80 \%$-, mas o evento contou ainda com um número expressivo de médicos, professores, estudantes, líderes sindicais, advogados, economistas, engenheiros, assistentes sociais, sociólogos, incluindo um químico, um atuário e uma urbanista.

A lista de presença do s.HRué composta por nomes que tiveram participação ativa na vida profissional e política brasileira. A mobilização foi expressiva e teve como presidente de honra João Goulart (já empossado no regime presidencialista) e como presidentes do evento os do IPASE e do IAB Nacional, e como diretores executivos, arquitetos que participaram na primeira etapa.

O documento resultante é bastante extenso e detalhado. Está dividido em nove considerações, dezoito afirmações e três propostas e complementa-se com diversas partes: I - De órgãos a executar; II - Da desapropriação para fins Habitacionais e de Planejamento Territorial; III - Prioridades de Atendimento e Normas de Controle; IV - Plano Nacional Territorial; V - Plano Nacional Habitacional; e, VI - Aquisição de Imóvel Locado (INSTITUTO DE ARQUITETOS DO BRASIL, 1963d).Vale indicar a importância e consistência das reflexões e das recomendações, discriminadas de forma coerente,e que representariam transformação de todo o arcabouço político administrativo do país.

Nas considerações observam-se questões contundentes inerentes à época, que associavam os problemas habitacionais a uma longa sucessão de fatos e processos espoliativos que levaram ao subdesenvolvimento da América Latina. 
Ressalta a crescente distância entre salário, renda e preços de locação e de aquisição de moradias argumentando que a situação era resultado de uma urbanização descontrolada, do incremento demográfico e das arcaicas relações de produção agrária e do surto industrial desordenado. O aumento crescente, em números absolutos e relativos de habitações subnormais, como favelas, cortiços, mocambos, malocas e barracos mostravam o problema da deficiência da moradia adequada em quantidade e qualidade. Indica também que o fato de que as habitações, mesmo permanentes, deterem deficiência de serviços públicos e de equipamentos urbanos e ainda demonstra a incapacidade do governo de prover com recursos e com investimentos suficientes e necessários ao aumento de oferta de moradia que atenda ao crescimento da população urbana. A confirmação pelos dados estatísticos da carência, mesmo que entendida por muitos como pouco precisa,reiterava a deficiência habitacional. A falta de uso de tecnologias adequadas e a ausência de uma política habitacional capaz de atender as carências verificadas mesmo que de conhecimento generalizado, não encontravam respostas adequadas do poder público.

A essa série de considerações precede a um discurso intenso e inflamado, de afirmações contundentes sobre a situação do país nesse domínio, acentuando aspectos fundamentais do direito do homem, a saber: 1) habitação como direito fundamental do homem e da família; 2) habitação não apenas como abrigo físico, devendo se ater a requisitos mínimos compatíveis com a saúde, eficiência e condições culturais exigidos por uma sociedade em desenvolvimento; 3) habitação atendendo a população em níveis compatíveis com o grau de civilização já atingido pelo país e não à margem de seu desenvolvimento econômico; 4) habitação sem contrastar com os conceitos de democracia e justiça social devendo superar sua carência com esforços para a racionalização de métodos de produção; 5) solução do problema habitacional associado a política de desenvolvimento econômico e social do País; 6) habitação como problema de responsabilidade do Estado; 7) política habitacional do Estado não podendo ser de ordem assistencial e paternalista, mas relacionada ao desenvolvimento global do País; 8) política habitacional associada à formação de consciência popular e a participação do povo em programas de desenvolvimento de comunidades; 9) política habitacional concretizada por meio de planos nacionais, territoriais e de habitação integrados ao planejamento global, nos níveis nacional, regional, estadual e municipal; 10) planejamento territorial e de habitação considerados pelos órgãos de planificação socioeconômica; 11) planejamento habitacional fundamentado nas necessidades habitacionais atuais e futuras, não regulado apenas pela capacidade de absorção dos construtores, que é relacionada aos 
níveis de preço das construções e dos aluguéis, incapazes de responder às populações menos favorecidas; 12) planejamento habitacional estabelecido com metas que atendam: a) a capacidade de amortização das diversas camadas da população; b) o tipo de moradia que atenda as dimensões adequadas a realidade regional, a situação econômica e demográfica, assim como a relação entre casa, trabalho, serviços e equipamentos urbanos e custos de infra estrutura urbana; 13) reforma urbana com mudança constitucional (referência ao § 16, art. 141 da Constituição Federal de 1946, que exige desapropriação com pagamento à vista e em dinheiro ${ }^{1}$; 14 ) política de locação de moradias urbanas de forma a relacionar o aluguel à renda familiar; 15) plano de medidas de emergência destinadas a melhoria da sub habitação dentro da realidade brasileira em bases locais, utilizando o esforço próprio, a ajuda mútua e o desenvolvimento comunitário; 16) medidas de cerceamento ao mercado imobiliário "disciplinando a especulação imobiliária no setor"; 17) medidas de melhoria de processos técnicos construtivos vinculados ao mercado em desenvolvimento; e, 18) criação de um órgão central federal com autonomia financeira (INSTITUTO DE ARQUITETOS DO BRASIL, 1963d).

Baseados nestes princípios foram propostas: 1) medidas do poder da República relacionadas à reformas de base, que viabilizassem a solução dos pontos levantados; 2) reforma da Constituição que suprima no artigo 141 (§ 16) as expressões "prévia" e "em dinheiro" permitindo ao Governo outras formas de indenização em caso de interesse social; e, 3) o envio ao Congresso Nacional de um projeto de lei contendo os princípios de uma política habitacional e de reforma urbana aprovadas no Seminário (INSTITUTO DE ARQUITETOS DO BRASIL, 1963d).

Interessa aqui a ressalva de que em Mensagem encaminhada ao Congresso Nacional na abertura da sessão legislativa de 1964 o Presidente da República João Goulart faz explícita menção aos resultados do s.HRu incorporando muitos de suas recomendações à seu plano de Governo.Nas palavras do presidente:

No que diz respeito ao exame do problema para a definição de princípios que deverão orientar a ação do poder público no âmbito nacional, cumpre citar o Seminário de Habitação e Reforma Urbana levado a efeito sob os auspícios do Instituto de Previdência e Assistência aos Servidores do Estado (IPASE), com a colaboração do Instituto de Arquitetos do Brasil (IAB), cujas conclusões

\footnotetext{
${ }^{1} \S 16$ - É garantido o direito de propriedade, salvo o caso de desapropriação por necessidade ou utilidade pública, ou por interesse social, mediante prévia e justa indenização em dinheiro. Em caso de perigo iminente, como guerra ou comoção intestina, as autoridades competentes poderão usar da propriedade particular, se assim o exigir o bem público, ficando, todavia, assegurado o direito a indenização ulterior [grifo nosso].
}

URBANA, V.6, no 8, jun.2014 - Dossiê: Cidade e Habitação na América Latina - CIEC/UNICAMP 
constituíram subsídio valioso para a fixação dos rumos que o Governo pretende imprimir a esse setor (GOULART, 1964 p. 199-200) ${ }^{2}$.

As mudanças conjunturais atreladas às propostas de reformas de base debatidas e defendidas pelo presidente João Goulart, incluída na proposição do primeiro item de propostas do s.HRu como acima elencado, não são contempladas.

Já no período de exceção após o golpe de março de 1964, é promulgada a Lei Federal no 4.380/1964 que cria o Banco Nacional da Habitação (BNH),o Serviço Federal de Habitação e Urbanismo (SERFHAU) e as Sociedades de Crédito Imobiliário - as Letras Imobiliárias - instituindo o sistema financeiro para aquisição da casa própria, a correção monetária nos contratos imobiliários de interesse social além de outras providências.De alguma forma essa Lei contempla princípios previstos do conjunto de considerações promovidas pelo documento final do s.HRu considerando basicamente o item 3 das proposições do Seminário. A título de exemplo, pode-se citar a própria criação do BNH, o órgão central federal com autonomia financeira. Essa autonomia era inicialmente prevista com recursos provenientes da compra compulsória de Letras Imobiliárias pelos SESIs e SESCs emitidas pelo Banco, receitas de Institutos de Aposentadorias e Pensões, e de todas as empresas do País que mantinham empregados sujeitos a descontos para esses Institutos,e também por meio de um montante dos depósitos efetuadas na Caixa Econômica Federal. Em 1966,

\footnotetext{
${ }^{2}$ Vale a pena conferir em alguns trechos da Mensagem de Goulart, a influência exercida pelos resultados do Seminário. A título de exemplo incluímos aqui alguns desses trechos: [...] O problema da habitação no Brasil apresenta aspectos da maior gravidade que podem ser traduzidos em um déficit crônico de caráter quantitativo e qualitativo. [...] São as "favelas" do Estado da Guanabara, do Estado do Rio de Janeiro e áreas circunvizinhas; os "mocambos" das regiões do norte e do nordeste; as "choças" ou "malocas" dos Estados do sul; as "invasões" do leste brasileiro, que constituem todas, em última análise, designações diferentes do mesmo problema, têm por origem as mesmas causas e produzem os mesmos efeitos maléficos nos que nelas vivem. A solução desse problema consistirá, evidentemente, em obra de largas proporções, cuja execução não caberá em um só período de governo e não está na dependência apenas de iniciativas da administração pública federal, mas exige, também, a colaboração de todos e, particularmente, do Poder Legislativo, ao qual esta reservada a relevante tarefa de aprovação de atos da maior importância, que constituem as bases para assegurar ao Governo os meios indispensáveis para uma ação decisiva. [...] Vários fatores dificultam, na conjuntura atual, a ação do poder público federal no combate à crise de moradias. [...] Em face da situação focalizada, verifica-se que somente mediante uma reestruturação geral e a reformulação dos princípios básicos que orientam, atualmente, a ação do poder público, poderá ser definida uma política habitacional de real interesse coletivo e consentâneo com a magnitude e a gravidade do problema. [...] A vista das limitações da legislação vigente e diante da carência de recursos financeiros, o Governo estuda a elaboração de normas de caráter regulamentar para coordenação da aplicação de recursos públicos e privados no setor, até o advento de nova legislação. [...] Nenhuma política habitacional válida pode, além do mais, basear-se em medidas de caráter repressivo ou policial; antes, deverá pautar-se em providência de natureza assistencial, porque destinadas a resolver ou pelo menos a atenuar problema de fundo eminentemente social. 0 deslocamento, por exemplo, de favelados não pode, por isso, ser imposto pela força, mas precedido de investigações sobre as condições de vida desses agrupamentos e amparado, de perto, pelas modernas técnicas do serviço social, para que não se criem outros tantos problemas de desajustamento, de transporte mais caro e difícil para os locais de trabalho e até mesmo de desemprego que invalidam, em grande parte, os benefícios decorrentes da transferência (GOULART, 1964 p. 196-203).
}

URBANA, V.6, no 8, jun.2014 - Dossiê: Cidade e Habitação na América Latina - CIEC/UNICAMP 
contudo, é criado o Fundo de Garantia de Tempo de Serviço (FGTS)porLei Federal n. 5.107, de 13 de setembro, responsável pela principal fonte de recursos a serem aplicados pelo Banco.

A Lei de criação do BNH contempla ainda alguns outros itens como a definição de uma política habitacional com o estabelecimento de metas com vistas à capacidade de amortização de camadas da população, em particular orientada às habitações subnormais em associação à política de desenvolvimento econômico e social do País.

Vale a ressalva de que a definição da política habitacional ficaria a cargo do Ministério de Planejamento, mas o Banco Nacional da Habitação é criado sob a égide do Ministério da Fazenda. Adicionalmente interessa mencionar que, a despeito de alguns dos princípios incluídos no documento do s.HRu terem sido contemplados, esses o foram de forma difusa e não integral sem levar em conta os anseios e participação da população interessada, aspectos culturais e sociais regionais, não tendo considerado outras formas de provisão de habitação a não ser o de propriedade privada, além de outros aspectos sociais e comunitários abarcados na essência nas proposições do Seminário.

Outro aspecto incluído no documento e referente ao item 2 de suas proposições só veio a ser atendido com a promulgação da Constituição de 1988, ainda que na Constituição de 1969 o tema é parcialmente abordado.

Após essas proposições, o documento final do Seminário esboça um perfil desejável para o órgão central executor recomendado pelo evento, suas atribuições, composição administrativa e fontes de recursos, inclusive com a criação de um fundo nacional de habitação. Esse deveria incluir um órgão executor financeiro sob a jurisdição do órgão central, que englobaria a Caixa Econômica Federal e seu Conselho Superior, e funcionaria como "Banco Nacional de Habitação". Os recursos originados do orçamento da União seriam vinculados ao programa de habitação e as despesas com o pessoal administrativo não deveriam ultrapassar a $10 \%$ do orçamento do fundo(INSTITUTO DE ARQUITETOS DO BRASIL, 1963d).

O documento se desdobra fazendo proposições acerca de normas para desapropriação para fins habitacionais e de planejamento territorial, prioridades de atendimento e normas de controle, plano nacional territorial, plano nacional de habitação e de aquisição de imóvel locado.

O órgão executor é exaustivamente delineado não apenas em suas formas de coordenação como também na discriminação de amplo arco de atividades, sua constituição em conselhos deliberativo e consultivo e departamentos técnicos, assim como indicava a admissão temporária de pessoal, permitindo contratos renováveis. 
Seu patrimônio é também discriminado, criando-se impostos com alíquotas diferenciadas, impostos de habitação nas operações imobiliárias de imóveis e loteamentos, arrecadação do selo de habitação, renda líquida da Loteria Federal e outras contribuições. Outro item assinala formas de desapropriação para fins habitacionais e de aproveitamento do território.

Essas sugestões parecem ter sido mais bem consideradas pela Lei de 1964 do que os itens acima examinados até porque o nome da instituição central responsável pela tarefa foi utilizado além da criação de um fundo nacional de habitação, ainda que não totalmente com a composição sugerida, além do envolvimento de instituições já existentes como a Caixa Econômica Federal.

No que se refere às prioridades de atendimento, o documento indica que deverá ser levado em conta a densidade e a dinâmica de crescimento da população, a densidade relativa de sub-habitação, a disponibilidade de recursos e a existência de planos de habitação locais e regionais. O órgão central proposto teria a responsabilidade de publicar anualmente os municípios integrantes das listas selecionadas, que deveriam preparar em um tempo estabelecido seus planos habitacionais. Este órgão poderá financiar e dar assistência técnica aos municípios e aos órgãos regionais de planejamento.

Enquanto o documento propõe um plano nacional territorial desenvolvido em 3 itens o plano nacional de habitação é detalhado em 12 itens denotando cuidado maior para seu equacionamento, que parece constituir a maior preocupação do Seminário.

O documento destaca a aquisição de imóvel locado e dá preferência de compra ao morador locatário assegurando a este o direito de adjudicação compulsória desde que se enquadre nos objetivos do plano de habitação proposto. $O$ documento se encerra com propostas e moções, votos, congratulações, repúdio além de manifestação sobre a inserção nos currículos estudantis de temas sobre a matéria.

As propostas finais são bastante diversificadas e merecem menção pelo seu alcance inovador. São elas: 1) sugestão de mudança no Imposto de Renda para aplicação na casa própria, 2) organização de comunidades disciplinando e orientando tecnicamente para o aproveitamento dos recursos dos grupos sociais, 3) aproveitamento da mão de obra ociosa local, 4) uso de metodologia adequada para o dimensionamento qualitativo e quantitativo da escassez de moradia, 5) providencias junto ao IBGE para a realização de censo específico de população e habitação de 1960, em que dados sobre habitação sejam apresentados isoladamente para cidades importantes e em conurbações e, 6) instituição de um sistema de estatísticas 
contínuas sobre a habitação quantitativa e qualitativa considerando a situação socioeconômica da população.

Essas propostas ao menos no âmbito da Lei n. 4.380 não foram contempladas. A organização comunitária era uma forma inconcebível no regime vigente no período e as recomendações específicas acerca das estatísticas e mapeamento das diversas formas de habitação não deram conta, por muitos anos, de estimar adequadamente o déficit habitacional do País.

Por fim, o documento chama a atenção sobre a necessidade dos órgãos existentes como a Caixa Econômica e os Institutos de Previdência acatar os princípios e normas deste Seminário. Propõe também que as grandes concentrações urbanas constituídas por mais de um município se consorciem para resolver os problemas comuns, especialmente os relativos à organização do território e habitacionais.

\section{CONCLUSÕES}

O que de mais relevante pode ser observado nessa análise do documento e seus desdobramentos são a atualidade de seus temas. Realizado num momento político de transição, um ano depois se deu a deposição do presidente da República e instalação do governo da ditadura. Esse governo permitiu que algumas de suas premissas e recomendações fossem assumidas pela Lei de criação do Banco Nacional de Habitação, em agosto de 1964. A sua viabilização se concretizou por conjugação de interesses da construção civil vinculados a correntes políticas conservadoras que emergiram no golpe militar pelas representações do Sindicato da Indústria da Construção Civil do Estado da Guanabara e da UDN local, através das figuras políticas, do governador do Estado da Guanabara Carlos Lacerda e de sua Secretária de Estado de Serviço Social Sandra Cavalcanti, que se tornou a primeira Presidente do BNH. Com uma carreira política expressiva no Estado, sua imagem ficou intimamenteassociada à carta que enviou ao primeiro presidente do período da ditadura, general Castello Branco, em que relatava: "[...] Achamos que a revolução [o golpe] vai necessitar agir vigorosamente junto às massas. Elas estão órfãs e magoadas, de modo que vamos ter que nos esforçar para devolver a elas uma certa alegria. Penso que a solução do problema da moradia, pelo menos nos grandes centros, atuará de forma amenizadora e balsâmica sobre suas feridas cívicas"(COLETIVO USINA, 2012, p. 94 apud, MARICATO, 1987). Ressalte-se que o documento final do s.HRuera do conhecimento geral da classe política, em particular da carioca e certamente pode servir de base a formulação do novo Banco, 
primordialmente gestado no Rio de Janeiro, ainda que as decisões ficassem centralizadas na capital federal, Brasília.

Interessa aqui ressaltar a originalidade, pioneirismo das discussões e reflexões promovidas pelo Seminário que só vieram a ser posteriormente assimiladas, concebidas e/ou atendidas após os debates responsáveis pela da Reforma Urbana concretizada por ocasião da promulgação da Lei n.10.257, de 10 de julho de 2001 do Estatuto das Cidades.

O lento processo de assimilação dos debates promovidos no 'Quitandinha', como ficou conhecido o Seminário, está nesse ano de 2013 comemorando 50 anos e permitiu ao IAB organizar um amplo debate nacional com os temas da atualidade, em que o balanço do documento de 1963 foi pouco contemplado. Fizeram parte da pauta de discussão questões que afligem a cidade "globalizada", ainda que estejam pendentes alguns problemas pretéritos. Como ilustração apresenta-se a agenda de 2013, do então denominado Q+50. Para tanto, o IAB Nacional e o Conselho de Arquitetura e Urbanismo - Brasil (CAU) organizaram eventos nos Departamentos Estaduais.

O Q+50 foi iniciado no Rio de Janeiro em fevereiro de 2013 com uma agenda temática nacional discutindo temas da atualidade. No Rio de Janeiro as discussões giraram em torno do temaDemocracia, cidade e metrópoles: democratizar cidades sustentáveis. No Rio Grande do Sul, no mês de abril, o temaMoradia brasileira:produção familiar, interface do formal e informal, a dinâmica do mercado imobiliário; aspectos sociais e o passivo habitacional foram 0 foco das discussões.Gestão das cidades: sistemas de planejamento, planos diretores, estratégicos, desenho urbano, governança metropolitana foi a temática do evento no Estado de São Paulo no mês de maio.Questões de Sustentabilidade urbana: a interação e os espaços urbanos; patrimônio e culturasão abordadas no evento ocorrido em junho no Distrito Federal. No mês de julho,Mobilidade urbana: transporte público, desenvolvimento e controle urbano, são os temas contemplados nas discussões promovidas em Minas Gerais. No Estado da Bahia o Esvaziamento dos centros: a dinâmica urbana e a expansão incontrolável é o tema que está previsto para o mês de agosto. A Amazônia urbana: o passivo sócio ambiental; saneamento, sistema hídrico, impactos socio-climáticos, serão os temas abordados em setembro no Estado do Amazonas.

Como se observa a temática habitação só aparece em um dos encontros e encontra concorrência com uma multiplicidade de problemas enfrentados pelas cidades brasileiras da atualidade. Interessa a ressalva de que aquestãohabitacional, 
tão presente cinquenta anos antes,não foi suficientementeabordada no escopo das preocupações do $Q+50$, evidenciando o esvaziamento dessa problemática diante do emaranhado de questões emergentes na contemporaneidade.

Os fatos apresentados nesse documento indicam que o s.HRu traz a questão habitacional como foco de uma Reforma Urbana para o País. O Banco Nacional da Habitação é posteriormente criado, influenciado pelas proposições do evento, e a despeito de sua produção de moradias, não conseguiu dar conta da questão, nem suas ações estiveram alinhadas com as premissa do S.HRu, tendo sido extinto em 1987.

\section{REFERENCIAS}

ARAÚJO, Brás José de. Politique estérieureet contradictions du capitalisme dépendant: Le gouvernement Jânio Quadros auBrésil. Tese (Doutorado em Ciências Políticas) - CycleSupérieur D'étudeset de Recherches Politiques - Centre Universitaire de Vincennes - Paris 8,Paris, 1970.

BENEVIDES, Maria Victoria de Mesquita. O governo Kubitschek: desenvolvimento econômico e estabilidade política - 1956 - 1961. Rio de Janeiro: Editora Paz e Terra, 1976.

BRESSER PEREIRA, Luís Carlos. Desenvolvimento e crise no Brasil: 1930 - 1967. Rio de Janeiro: Zahar Editores, 1968.

COLETIVO USINA. Reforma urbana e autogestão na produção da cidade: história de um ciclo de lutas e desafios para a renovação da sua teoria e prática. In: BENINI, Édi A.,FARIA Maurício Sardá de, NOVAES, Henrique T. e DAGNINO, Renato (Org.). Gestão pública e sociedade: fundamentos e políticas públicas de economia solidária. São Paulo: Outras Expressões, 2012, p. 81-120. Disponível em:http://www.usinactah.org.br/files/Gestores.pdf Acesso em: 26 jul. 2013.

GORELIK, Adrien, A produção da cidade latino-americana. Tradução Fernanda Areas Peixoto. In: Revista Tempo Social. São Paulo, v. 17 n. 1, 2005, p.111-133.

GOULART, João. Mensagem ao Congresso Nacional - 1964. In: Biblioteca da Presidência da República. Brasília. Disponível em: http://www.institutojoaogoulart.org.br/upload/conteudos/120128180216 joao go ulart mensagem ao co.pdf Acesso em: 28 de jul. 2013.

INSTITUTO DE ARQUITETOS DO BRASIL. Ainda a tal da reforma urbana. Revista Arquitetura, Rio de Janeiro: n. 23, maio 1964. 
INSTITUTO DE ARQUITETOS DO BRASIL. Documentação s.HRu. Revista Arquitetura, Rio de Janeiro: n. 15, set. 1963d.

INSTITUTO DE ARQUITETOS DO BRASIL. Editorial s.HRu. Revista Arquitetura, Rio de Janeiro: n. 14, ago. 1963c.

INSTITUTO DE ARQUITETOS DO BRASIL. Editorial s.HRu. Revista Arquitetura, Rio de Janeiro: n. 13, jul. 1963b.

INSTITUTO DE ARQUITETOS DO BRASIL. s.HRu dá frutos em Porto Alegre. Revista Arquitetura, Rio de Janeiro: n. 18, dez. 1963 e.

INSTITUTO DE ARQUITETOS DO BRASIL. Seminário de Habitação e Reforma Urbana. Revista Arquitetura, Rio de Janeiro: n. 12, jun. 1963a.

JAGUARIBE, Hélio. Desenvolvimento econômico e desenvolvimento político. Rio de Janeiro: Editora Paz e Terra, 1969.

LAFER, Celso. O planejamento no Brasil: observações sobre o plano de metas - 19561961.In: LAFER, Betty Mindlin. Planejamento no Brasil. São Paulo: Editora Perspectiva, 1970.

QUINTO JR., Luiz de Pinedo.Nova legislação urbana e os velhos fantasmas. Estudos Avançados, São Paulo: v. 17, n. 47, p. 187-196, 2003.

REPÚBLICA FEDERATIVA DO BRASIL. Lei no 4.380, de 21 de agosto de 1964. Presidência da República. Casa Civil. Subchefia de Assuntos Jurídicos. Brasília. Disponível em: http://www.planalto.gov.br/ccivil 03/leis/L4380.htm Acesso em: 26 jul. 2013.

RIBEIRO, Cecilia e PONTUAL, Virginia. A reforma urbana nos primeiros anos da década de 1960. Arquitextos. 109.07, ano 10, jun. 2009. Disponível em: http://www.vitruvius.com.br/revistas/read/arquitextos/10.109/50 Acesso em: 30 jul. 2013.

SERRAN, João Ricardo. O IAB e a política habitacional brasileira: 1954 - 1975. São Paulo: Schema Editora Ltda. 1976. 